\title{
AVALIAÇÃO DA ATIVIDADE ANTIVIRAL DE COMPOSTOS DERIVADOS DA 2- PICOLILAMINA DA CLASSE DA 4-TIAZOLIDINONA CONTRA O VÍRUS DA DIARREIA VIRAL BOVINA
}

CASTRO, Clarissa Caetano de ${ }^{1}$; SILVA, Débora Scopel e ${ }^{1}$; BAREÑO, Valéria Dias de Oliveira ${ }^{2}$; LIMA, Marcelo de ${ }^{3}$; CUNICO, Wilson ${ }^{4}$; HÜBNER, Silvia de Oliveira ${ }^{3}$.

${ }^{1}$ Doutoranda do Programa de Pós-Graduação em Veterinária da UFPEL, ${ }^{2}$ Doutoranda do Programa de Pósgraduação em Química Tecnológica e Ambiental da FURG, ${ }^{3}$ Professor Doutor do Departamento de Veterinária Preventiva da UFPEL ${ }^{4}$ Professor Doutor do Centro de Ciências Químicas, Farmacêuticas e de Alimentos da UFPEL.

\section{RESUMO}

$\mathrm{D}$ entre as propriedades biológicas das moléculas derivadas da classe da 4tiazolidinona, a atividade antiviral tem atraído a atenção dos pesquisadores. Neste estudo, foi determinada a citotoxicidade e a atividade antiviral de cinco compostos derivados da 2-picolilamina da classe da 4-tiazolidinona (V19, V20, V23, V28 e V29) frente ao vírus da diarreia viral bovina (BVDV) em células MDBK (Madin-Darby Bovine Kidney). A atividade antiviral foi determinada pela comparação entre os títulos obtidos pelo método de diluição limitante na presença ou ausência de cada molécula. As moléculas V20 e V28 na maior concentração não citotóxica foram capazes de inibir a produção das partículas virais, reduzindo os títulos virais quando comparadas com o controle, e resultaram em um percentual de inibição de $78 \%(p<0,01)$ contra o BVDV. As moléculas V20 e V28 foram consideradas não tóxicas nas concentrações $0,063 \mathrm{mg} / \mathrm{mL}$ e $0,07 \mathrm{mg} / \mathrm{mL}$, respectivamente, quando avaliadas através do ensaio de vermelho neutro como método de determinação da viabilidade celular. As outras tiazolidinonas avaliadas (V19, V23 e V29) não demonstraram atividade contra o BVDV e foram tóxicas acima de $0,078 \mathrm{mg} / \mathrm{mL}$. Em conclusão, os compostos V20 e V28 derivados da 2-picolilamina da classe da 4-tiazolidinona apresentaram atividade antiviral frente ao BVDV, o que os tornam alvos para mais estudos visando elucidar seus mecanismos de ação antiviral.

Palavras-chave: Tiazolidinonas. Citotoxicidade. Atividade antiviral. 


\section{INTRODUÇÃO}

O vírus da diarreia viral bovina (BVDV) é responsável por importantes perdas na produção de carne e leite. A enfermidade é considerada uma das principais doenças que acometem bovinos (LINDBERG, 2003). O BVDV causa diversas manifestações clínicas em bovinos, que podem ser reunidas em quatro formas principais: doença aguda leve (gastrentérica e respiratória), doença aguda severa (gastrentérica, respiratória e hemorrágica), doença das mucosas (DM) e BVD crônica. Entretanto, as maiores consequências causadas por esse agente relacionam-se com prejuízos de ordem reprodutiva, como abortos e infertilidade. $\mathrm{A}$ infecção durante um determinado período do desenvolvimento fetal também pode estabelecer o nascimento de animais persistentemente infectados, os quais se mantêm em viremia durante toda a vida e são importantes fontes de disseminação do vírus (FLORES et al., 2005). Além disso, o BVDV pode ser um contaminante de produtos biológicos como o soro fetal bovino, utilizado no cultivo de linhagens celulares (ERICKSON et al., 1991). No Brasil não há programas oficiais para controle e/ou erradicação do BVDV e, embora existam vacinas disponíveis, o vírus mantém-se endêmico na população (PAESHUYSE et al., 2006).

O tratamento com compostos que atuem especificamente contra o vírus pode ser uma alternativa adequada em determinadas ocasiões (PAESHUYSE et al., 2006). A disponibilidade de um antiviral pode ser altamente benéfico para o tratamento de linhagens celulares contaminadas (DURANTEL et al., 2004), na produção de embriões in vitro (STRINGFELLOW et al., 2005), tratamento de animais reprodutores ou de alto valor genético, ou ainda, para tratamento de animais silvestres em cativeiro (PAESHUYSE et al., 2006).

As moléculas derivadas da classe da 4-tiazolidinona são substâncias heterocíclicas que se destacam devido a sua vasta aplicação no campo medicinal (JAIN et al., 2012). Há descrições de propriedades antibacteriana e antifúngica (EL-GABY et al., 2009); antiviral contra o vírus da imunodeficiência humana tipo 1 (HIV-1) (TRIPHATI et al., 2014), o vírus da hepatite C (HCV) (LEMM et al., 2010), o vírus da dengue (DENV) (NITSCHE et al., 2013) e o vírus chikungunya (CHICK-V) (JADAV et al., 2015); anti-inflamatória e analgésica (ELEFTHRIOU et al., 2012); antitumoral (GUDUDURU et al., 2004); anticonvulsivante e antipsicótica (KAUR et al., 2010). 
Neste sentido, este trabalho analisou a citotoxicidade e o potencial antiviral de cinco substâncias derivadas da 2-picolilamina da classe da 4-tiazolidinona frente ao vírus da diarreia viral bovina em células MDBK (Madin-Darby bovine kidney).

\section{MATERIAL E MÉTODOS}

\section{Cultivo Celular e Vírus}

Células MDBK (ATCC ${ }^{\circledR}$ Number: CCL22 $^{\mathrm{TM}}$, USA) foram cultivadas em meio essencial mínimo (E-MEM, Sigma Aldrich, USA) suplementado com soro fetal bovino (Gibco, USA), penicilina (Sigma-Aldrich, USA), estreptomicina (Vetec, Brasil), enrofloxacina (Bayer, Brasil) e anfotericina B (Cristália, Brasil) a $37{ }^{\circ} \mathrm{C}$ em uma estufa contendo $5 \%$ de $\mathrm{CO}_{2}$. A cepa NADL citopática do BVDV foi fornecida pelo Setor de Virologia da Universidade Federal do Rio Grande do Sul. Os estoques do vírus foram preparados e as alíquotas mantidas a $-70{ }^{\circ} \mathrm{C}$ até o momento do uso.

\section{Síntese das Moléculas}

Foram utilizadas neste estudo cinco moléculas derivadas da 2-picolilamina da classe da 4tiazolidinona. Os compostos foram obtidos de acordo com a metodologia recentemente descrita pelo grupo de pesquisa do Dr. Cunico (MARQUES et al., 2014). A estrutura das moléculas denominadas V19, V20, V23, V28 e V29 estão demonstradas na Figura 1. Cada molécula foi diluída em dimetilsulfóxido (Synth ${ }^{\circledR}$, Brasil) e estocada à temperatura ambiente até o momento da utilização. 

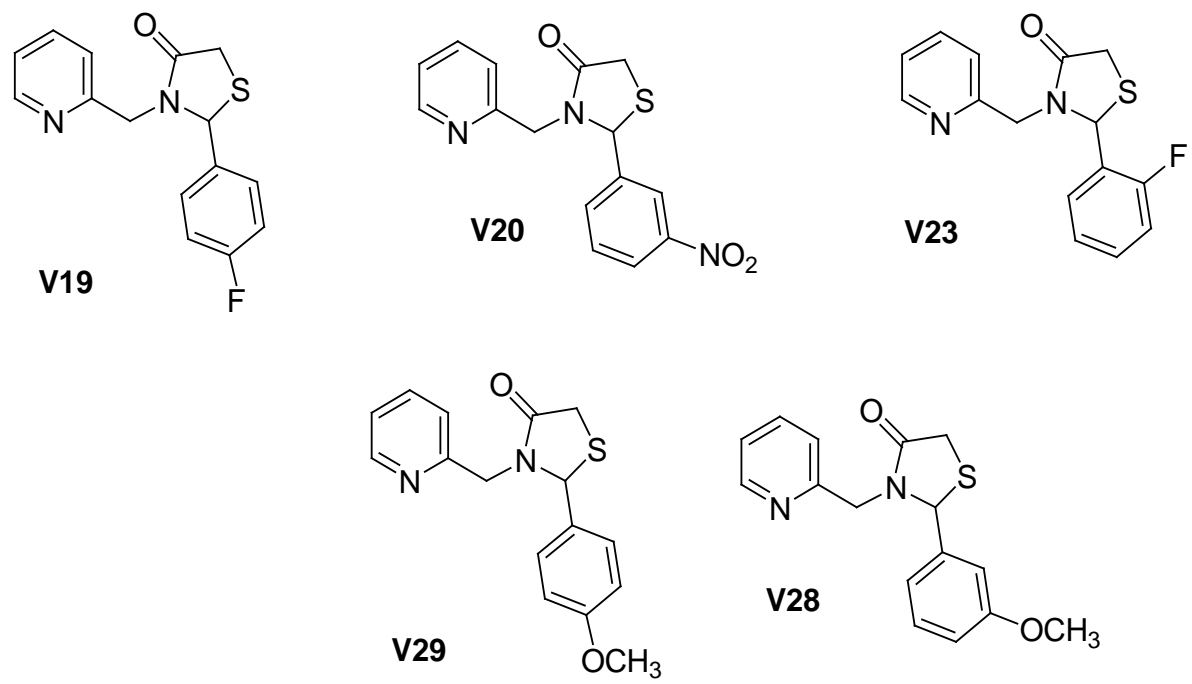

Figura 1- Estrutura geral das moléculas estudadas.

\section{Avaliação da Citotoxicidade}

O ensaio foi realizado em microplacas de poliestireno com 96 cavidades, em quadruplicada, e repetido três vezes. Após 24 horas de confluência celular foram adicionadas diferentes concentrações das moléculas $(0,63$ a $0,0063 \mathrm{mg} / \mathrm{mL})$. As viabilidades celulares foram avaliadas pela observação microscópica diária das alterações morfológicas das células e mensuradas pelo ensaio vermelho neutro (BORENFREUND; PUERNER, 1984) após 72 horas de incubação. A porcentagem de células viáveis foi calculada mediante a fórmula AT/AC $x$ 100, sendo AT e AC a absorbância dos tratados e a absorbância dos controles, respectivamente (VAUCHER et al., 2010). As leituras das densidades ópticas foram quantificadas em espectrofotômetro em comprimento de onda de $540 \mathrm{~nm}$. Foram consideradas concentrações não tóxicas as que permitiram uma viabilidade celular maior que $90 \%$ quando comparada com o controle (células não tratadas). A partir do ensaio foi determinada a maior concentração não citotóxica (MNCC) de cada molécula.

\section{Avaliação da Atividade Antiviral}

A avaliação da atividade antiviral das moléculas foi realizada comparando a diferença entre o título viral nas células não tratadas e tratadas com os compostos nas concentrações não citotóxicas e expressa pelo percentual de inibição viral (PI). O PI foi calculado pela fórmula: $\mathrm{PI}=[1-($ antilog do título do tratado/antilog do título do controle)]×100 (NISHIMURA et al., 
1977). Os títulos virais foram calculados pelo método de diluição limitante (BEHRENS; KÄRBER, 1935) e expressos como dose infectante a 50\% do tecido celular em $100 \mu \mathrm{L}$ $\left(\mathrm{TCID}_{50} / 100 \mu \mathrm{L}\right)$ após 72 horas de incubação a $37{ }^{\circ} \mathrm{C}$. Os ensaios foram realizados em triplicata.

\section{Análise Estatística}

O teste $t$ de Student foi realizado para comparar os títulos virais com ou sem tratamento. Os valores foram considerados significativos quando $p<0,01$.

\section{RESULTADOS E DISCUSSÃO}

As toxicidades das moléculas derivadas da 2-picolilamina da classe da 4-tiazolidinona em células MDBK foram variáveis. Foram consideradas como não tóxicas as concentrações utilizadas que não resultaram em alterações nas células quando visualizadas no microscópio invertido e que obtiveram viabilidade superior a $90 \%$ quando analisadas pelo ensaio do vermelho neutro. As moléculas V19, V23 e V29 foram tóxicas acima de 0,078 mg/mL (91\% de viabilidade celular) e as concentrações não tóxicas das moléculas V20 e V28 foram a partir de $0,063 \mathrm{mg} / \mathrm{mL}$ e $0,07 \mathrm{mg} / \mathrm{mL}$, respectivamente ( $92 \%$ de viabilidade celular). Essas concentrações foram utilizadas para avaliar atividade anti-BVDV.

A partir das titulações realizadas e posterior análise estatística foi observada uma inibição na produção de partículas virais na presença das moléculas V20 e V28 quando comparadas com o controle (ausência das moléculas). As duas moléculas reduziram os títulos virais de $10^{3,25}$ para $10^{2,6} \mathrm{TCID}_{50} / 100 \mu \mathrm{L}$, resultando em um PI de 78\% ( $\left.\mathrm{p}<0,01\right)$. As moléculas V19, V23 e V29 não exerceram atividade sobre o BVDV, visto que não houve diferença entre os títulos virais na presença destas substâncias quando comparadas com o controle.

Estudos utilizando as mesmas moléculas avaliadas no presente estudo demonstraram atividade antioxidante (BOSENBECKER et al., 2014) e antifúngica (MARQUES et al., 2014). Outros pesquisadores já descreveram resultados promissores de atividade antiviral de algumas substâncias derivadas das tiazolidinonas. Triphati et al. (2014) relataram ação inibidora do análogo 2',6'-di-halofenil-tiazolidinona sobre a enzima transcriptase reversa do HIV-1. Foi determinada ação do composto BMS-824 (derivado das tiazolidinonas, com o 
radical fenilacetamida), sobre a proteína NS5A do vírus da hepatite C (LEMM et al., 2010). Nitsche et al. (2013) evidenciaram a inibição da protease do DENV pela adição do grupo 5arilideno-tiazolidinona. Recentemente, Jadav et al. (2015) citam a ação da molécula arilalquilideno-tiazolidinona sobre a protease nsp2 do CHICK-V. No presente trabalho não foi determinado o mecanismo de ação das moléculas V20 e V28 sobre o BVDV, mas novos estudos serão realizados visando elucidar os mecanismos de ação dos antivirais e a identificação das etapas da infeç̧ão nas quais ocorrem a ação das moléculas.

\section{CONCLUSÃO}

As substâncias V20 e V28 derivadas da 2-picolilamina da classe da 4-tiazolidinona demonstraram atividade antiviral frente o BVDV, evidenciando a necessidade de novos estudos para determinar o mecanismo de ação.

\section{EVALUATION OF THE ANTIVIRAL ACTIVITY OF COMPOUNDS DERIVATED OF 2- PICOLYLAMINE FROM THE CLASS OF 4-THIAZOLIDINONE AGAINST BOVINE VIRAL DIARRHEA VIRUS}

\section{ABSTRACT}

A mong the biological properties of the molecules derived from the class of thiazolidinones, the antiviral activity has attracted the attention of researchers. In this study, the cytotoxicity and antiviral activity of five compounds derived from 2picolylamine, from the 4-thiazolidinones class (V19, V20, V23, V28 and V29), were determined against the bovine viral diarrhea virus (BVDV) in MDBK (Madin-Darby Bovine Kidney) cells. The antiviral activity was determined by comparison among the titers obtained by limiting dilution in the presence or in the absence of each molecule. V20 and V28, in higher non-cytotoxic concentrations, were able to inhibit the production of viral particles, reducing the viral titers when compared with the control, and resulted in a percent of inhibition of $78 \%(p<0.01)$ against BVDV. V20 and V28 were considered non-toxic in the concentrations of $0.063 \mathrm{mg} / \mathrm{mL}$ and $0.07 \mathrm{mg} / \mathrm{mL}$, respectively, when analyzed with the method of the neutral red dye uptake to determine cell viability. The other compounds evaluated (V19, V23 and V29) did not demonstrate activity against BVDV and were toxic above $0.078 \mathrm{mg} / \mathrm{mL}$. In conclusion, the compounds V20 and V28 derived of 2-picolylamine, from the 4-thiazolidinone class, presented antiviral activity against BVDV, what makes them targets for further studies to elucidate the mechanism of antiviral action.

Keywords: Thiazolidinones. Cytotoxicity. Antiviral activity. 


\section{EVALUACIÓN DE LA ACTIVIDAD ANTIVIRAL DE COMPUESTOS DERIVADOS DE LA 2-PICOLILAMINA DE LA CLASE 4-TIAZOLIDINONA CONTRA EL VÍRUS DE LA DIARREA VIRAL BOVINA}

\section{RESUMEN}

$\mathrm{D}$ entro de las propiedades biológicas de las moléculas derivadas de la clase de las tiazolidinonas, la actividad antiviral ha atraído la atención de los investigadores. En este estudio, fue determinada la citotoxicidad y la actividad antiviral de cinco compuestos derivados de la 2-picolilamina de la clase 4-tiazolidinona (V19, V20, V23, V28 y V29) frente al virus de la diarrea viral bovina (VDVB) en células MDBK (Madin-Darby Bovine Kidney). La actividad antiviral fue determinada mediante la comparación entre los títulos obtenidos por el método de la dilución limitante mediante la presencia y/o ausencia de cada molécula. Las moléculas V20 y V28 en la mayor concentración no citotóxica fueron capaces de inhibir la producción de partículas virales, reduciendo los títulos virales en comparación con el control y resultando en un porcentaje de inhibición de $78 \%(p<0,01)$ en contra de VDVB. Las moléculas V20 y V28 fueron consideradas no tóxicas en las concentraciones de $0,063 \mathrm{mg} / \mathrm{ml}$ y de $0,07 \mathrm{mg} / \mathrm{ml}$, respectivamente, cuando fueron evaluadas a través del ensayo del rojo neutro utilizado como método de determinación de viabilidad celular. Los otros compuestos evaluados (V19, V23 y V29) no demostraron actividad frente al VDVB y eran tóxicos por encima de $0,078 \mathrm{mg} / \mathrm{mL}$. En conclusión, los compuestos V20 y V28 derivados de la 2-picolilamina pertenecientes a la clase de 4-tiazolidinona presentaron actividad antiviral frente al VDVB, que se convierten en objetivos de más estudios para elucidar el mecanismo de acción antiviral.

Palabras clave: Tiazolidinonas. Citotoxicidad. Actividad antiviral.

\section{REFERÊNCIAS}

BEHRENS, B.; KÄRBER, C. Wie sind reichenversuche fur biologische auswertungen am zweckmassigsten anzwordnen? Naunyn Schmiedeberg's Archives of Pharmacology, Ingelheim, v. 177, p. 379-388, 1935.

BORENFREUND, E.; PUERNER, J. A. A simple quantitative procedure using monolayer culture for toxicity assays (HTD/NR-90). Journal of Tissue Culture Methods, v. 9, p. 7-9, 1985.

BOSENBECKER, J.; BAREÑO, V. D.; DIFABIO, R.; et al. Synthesis and antioxidant activity of 3(Pyridin-2-ylmethyl)-1,3-thiazinan(thiazolidin)-4-ones. Journal of Biochemical Molecular Toxicology, v. 28, n. 9, p. 425-432, 2014. 
DURANTEL, D.; CARROUE'E-DURANTEL, S.; BRANZA-NICHITA, N.; et al. Effects of interferon, ribavirin, and iminosugar derivatives on cells persistently infected with noncytopathic bovine viral diarrhea virus. Antimicrobial Agents and Chemotherapy, v. 48, n. 2, p. 497-504, 2004.

ELEFTHERIOU, P.; GERONIKAKI, A.; HADJIPAVLOU-LITINA, D.; et al. Fragment-based desing, docking, synthesis, biological evaluation and struture-activity relationships of 2benzo/benzisothiazolimino-5-aryliden-4-thiazolidinones as cycloxygenase/lipoxygenase inhibitors. European Journal of Medicinal Chemistry, v. 47, n. 1, p. 111-124, 2012.

EL-GABY, M. S.; EL-HAG ALI, G. A.; EL-MAGHRABY, A. A.; et al. Synthesis, characterization and in vitro antimicrobial activity of novel 2-thioxo-4-thiazolidinones and 4,4' -bis (2-thioxo-4thiazolidinone-3-yl) diphenylsulfones. European Journal of Medicinal Chemistry, v. 44, n. 10, p. 4148-4152, 2009.

ERICKSON, G. A.; BOLIN, S. R.; LANDGRAF, J. G. Viral contamination of fetal bovine serum used for tissue culture: risks and concerns. Developments in Biological Standardization, $v$. 75, p. 173-175, 1991.

FLORES, E. F.; WEIBLEN, R.; VOGEL, F. S. F.; et al. A infecção pelo vírus da Diarréia Viral Bovina (BVDV) no Brasil-histórico, situação atual e perspectivas. Pesquisa Veterinária Brasileira, v. 25, n. 3, p. 125-134, 2005.

GUDUDURU, V.; HURH, E.; DALTON, J. T.; et al. Synthesis and antiproliferative activity of 2aryl-4-oxo-thiazolidin-3-yl-amides for prostate cancer. Bioorganic \& Medicinal Chemistry Letters, v. 14, n. 21, p. 5289-5293, 2004.

JADAV, S. S.; SINHA, B. N.; HILGENFELD, R.; et al. Thiazolidone derivaties as inhibitors of chikungunya virus. European Journal of Medicinal Chemistry, v. 89, p. 172-178, 2015.

JAIN, A. K.; VAIDYA, A.; RAVICHANDRAN, V.; et al. Recent developments and biological activities of thiazolidinone derivatives: a review. Bioorganic \& Medicinal Chemistry, v. 20, n. 11, p. 3378-3395, 2012.

KAUR, H.; KUMAR, S.; VISHWAKARMA, P.; et al. Synthesis and antipsychotic and anticonvulsant activity of some new substituted oxa/thiadiazolylazetidinonyl/thiazolidinolcarbazoles. European Journal of Medicinal Chemistry, v. 45, n. 7, p. 2777-2783, 2010.

LEMM, J. A.; O’BOYLE, D.; LIU, M.; et al. Identification of hepatitis C virus NS5A inhibitors. Journal of Virology, v. 84, n. 1, p. 482-491, 2010.

LINDBERG, A. L. Bovine viral diarrhea virus infections and its control. A review. Veterinary Questions, v. 25, p. 1-16, 2003. 
MARQUES, G. H.; KUNZLER, A.; BARENO, V. D. O.; et al. Antifungal Activity of 3-(heteroaryl-2ylmethyl) thiazolidinone derivatives. Medicinal Chemistry, v. 10, p. 355-360, 2014

NISHIMURA, T.; TOKU, K.; FUKUYASU, H. Antiviral compounds. XII. Antiviral activity of aminohydrazones of alkoxyphenyl-substituted carbonyl compounds against influenza virus in eggs and mice. Kitasato Archives of Experimental Medicine, v. 50, n. 1-2, p. 39-46, 1977.

NITSCHE, C.; SCHREIER, V. N.; BEHNAM, M. A. M.; et al. Thiazolidinone-peptide hybrids as dengue virus protease inhibitors with antiviral activity in cell culture. Journal of Medicinal Chemistry, v. 56, n. 21, p. 8389-8403, 2013.

PAESHUYSE, J.; LEYSSEN, P.; MABERY, E.; et al. A novel, highly selective inhibitor of pestivirus replication that targets the viral RNA-dependent RNA polymerase. Journal of Virology, v. 80, n. 1, p. 149-160, 2006.

STRINGFELLOW, D. A.; RIDDELL, K. P.; GIVENS, M. D.; et al. Bovine viral diarrhea virus (BVDV) in cell lines used for somatic cell cloning. Theriogenology, v. 63, n. 4, p. 1004-1013, 2005.

TRIPATHI, A. C.; GUPTA, S. J.; FATIMA, G. N.; et al. 4-Thiazolidinones: The advances continue...European Journal of Medical Chemistry, v. 72, p. 52-77, 2014.

VAUCHER, R. A.; TEIXEIRA, M. L.; BRANDELLI, A. Investigation of the citotoxicity of antimicrobial peptide P40 on eukaryotic cells. Current Microbiology, v. 60, n. 1, p. 1-5, 2010. 